\title{
The Future of the Institute of Ophthalmology
}

\author{
R K BLACH \\ London
}

We live in an age when the consequences of scientific discovery are increasingly impinging on our traditional social structures and behaviour. Thus, the contributions of science to industry are being modified by environmentalists, the contributions of biology to the human condition are being checked by moralists and philosophers, and the contributions of science to social behaviour and war are being questioned by the young of all nations. It is not surprising, therefore, that the purpose of science and the function of universities are being questioned. We at the Institute of Ophthalmology are not immune to these larger questions.

Looked at from the vantage point of an earlier age, the freedom and affluence of our society must be enviable, able as we are to exploit our talents irrespective of our backgrounds, our opinions or our masters. By comparison, some of the causes championed today must appear trivial. However, quite obviously, we do not live in Utopia which may well be a very unstimulating place. Some graffiti outside a Swiss town proclaimed "This town is dying of peace and good order" - a reminder that stress and conflict may be a necessary part of our lives.

We may consider the future of the Institute in terms of its Science, its Staff and its Finances.

\section{Science}

With the growth of so many bodies enquiring into the direction of science and the multiplication of so many intermediary disciplines, such as "education" and "administration", there is a danger that there may not be enough scientists actually to do the work. Obviously the Institute has to be selective in the science that it undertakes, determined by its existing facilities, the talents of its staff, and its policy decisions insofar as they decide future recruitment. Its approach needs to be multidisciplinary, since ultimately it is an institute of applied science. Nevertheless, the disciplines of basic science should be available. For example, the investigation of retinal function, both to study normal retina and disease mechanisms, might on the one hand be the precursor to creating an artificial retina, and on the other to finding cures for genetic and degenerative diseases. Such studies would involve the various skills that go under the umbrella of neurobiology.

Institute research should be applied, for example using laser technology to solve specific surgical problems. Such research could be contractual, derived from industry, for example in the developments of new types of contact lenses or the assessment of ophthalmic drugs. Sociological research, using the tools of epidemiology and statistics, could be used in preventive medicine. Lastly there should always be a place for "blue sky" research in the interests of academic freedom and serendipity.

While research strategy will certainly give a sense of direction to work being undertaken, it should not be so rigid as to exclude pragmatism where new problems arise or new tools and talents become available. Thus, for example, the exploitation of immunological techniques to tackle problems associated with uveitis will be determined by scientists with particular talents. It is this mixture of direction and freedom which is most likely to achieve results in scientific research.

\section{Staff}

The Institute depends upon the quality of its staff. It has been argued that security of tenure in universities in the past has led to indolence in some. Yet, where there is no security, anxiety can affect the quality of work. In order to attract talented people to go into scientific research some form of career structure is required which, 
on the one hand, can give rise to high rewards and, on the other, will maintain a degree of responsibility towards those whose creativity may decline with age. Education, designed to impart knowledge at all ages in life, has become an enormous industry and it should be possible to find dignified and worthwhile posts within the system for those who may start as researchers but may eventually spend more time in teaching or related activities. While not supporting the "Porterhouse Blue" philosophy, a ruthless policy is not acceptable; a middle way with increased mobility is possible.

\section{Finance}

Unless Government decides to privatise the universities it will maintain a basic financial interest in them. Increasingly, however, universities will need to justify their existence by their products. Universities indeed do create products that are in great public demand. These include education, research and development as well as services. The Institute of Ophthalmology has great demands on its teaching capabilities and these could certainly be extended. They include providing teaching and teaching material for medical undergraduates, general practitioners, other doctors, ophthalmologists in training, mature ophthalmologists, optometrists, orthoptists, nurses, scientists, paramedical workers, patients themselves and the public at large. Its research activities may well be associated with industry such as the optical industry, medical instrument makers and drug firms. The exploitation and patenting of inventions should be an important function. In association with the hospital, demographic surveys on ophthalmic diseases and its prevention should be among the most important of its services.

In order to undertake the manifold functions suggested for the Institute in the future within a finite space, plans are already being developed. These include the enlargement of its educational facilities, the extension of its laboratories, the improvement in the efficiency of its association with the hospital through an Institute/Hospital interface, and the creation of new workshops. In order to increase its association with the outside world the possibilities of an ophthalmic technology research centre and an ophthalmic trade centre are being considered.

We began this essay questioning the purpose of science and the function of the universities. We end with some specific proposals as the contribution of the Institute of Ophthalmology to those larger questions that concern us all. 